\title{
APPLICATION OF THE ELASTIC-PLASTIC MODEL IN THE ANALYSIS OF THE DISPLACEMENT IN A ROCK MASS
}

\author{
Halina Marczak ${ }^{1}$ \\ 1 Mechanical Engineering Faculty, Lublin University of Technology, Nadbystrzycka 36, 20-618 Lublin, Poland, \\ e-mail: h.marczak@pollub.pl
}

Received: 2017.12.05

Accepted: 2018.04.10

Published: 2018.06.01

\begin{abstract}
The concern of this article is the analysis of the impact of increased volume (dilation) and decreased strength of the rock material in the plastic zone on the displacement field in the vicinity of the roadway. Elastic-plastic model of the behaviour of the rock material and the strength criterion of Coulomb-Mohr were assumed. The volume change of the rock material is controlled by the angle of dilation $\psi$, which determines dilation parameter $\beta$ that is taken into account in the analysis. The influence of parameter $\beta$ and the strength of the rock material, after crossing the border state of stress, in the field of displacements in the vicinity of the excavation and rock pressure on the elastic support of the excavation was proved. The relationships determining displacement fields in the plastic zone which were obtained with consideration to in this zone of both the elastic and plastic displacement, as well as the relationships which were obtained without elastic deformations was discussed. The exact form of the equation for the displacement field in the plastic zone depends on how the elastic deformation in the plastic zone is defined. There are three ways of describing these deformations. In the first method it is assumed that in plastic deformation area the elastic deformation constants are equal to the deformation constants at the plastic and elastic border. The second method of description is based on the assumption that the plastic zone is a thick-walled ring whose edges: internal and external have been appropriately debited. In the third method, elastic deformations in the plastic zone were made dependent on the state of stress in the zone. The results are illustrated in a form of response curves of the rock mass.
\end{abstract}

Keywords: state of displacement, roadway, elastic-plastic model, response curve of the rock mass, dilatation, decreased strength of rock material, reducing the strength of the rock material, Coulomb-Mohr criterion.

\section{INTRODUCTION}

The analysis of the state of stress and displacement, and the analysis of the disturbed areas in the vicinity of underground (tunnel) excavations are important research problems of rock mechanics. The solutions in this area are used in mining engineering, oil and gas engineering and construction engineering. In particular, they are used in the design of excavation mining (tunnels), stability analysis of roadways and shafts, test holes and wells for oil and gas. In the literature there are numerous works presenting solutions describing the distribution of stresses and displacements around the mine excavations (tunnels) [1]. Many of these solutions are based on the concept of response curves of rock mass and support [11] and elastic-plastic [2,4] or the elastic-brittle-plastic [14] models of the behaviour of the rock material, taken to the analytical description of the curves. An interesting discussion on the practical application of the convergence- 
confinement method for the design of a circular tunnel made in elastic-plastic Coulomb-Mohr and Hoek-Brown centres was presented by Oreste [10]. Gschwandtner [6] presented a method to evaluate the behaviour of the rock mass using three curves: response curve of the rock mass, the support response curve and the curve of longitudinal deformations. Based on these curves Gschwandtner [6] conducted an analysis of the effects of possible actions to enhance the rock mass (bonding, concrete spraying). Among the works presenting an analytical method to assess the behaviour of the rock mass in the vicinity of excavations on the model response curves rock mass and support one can include the work by Pilecki [12]. Many authors' researches were focused on demonstrating the impact of the properties of the rock material on the state of stress and strain in the vicinity of the excavation, for example, Carranza-Torres [3], Marczak [8] discussed the issue of the impact angle of internal friction in the radial displacement contour of the excavation and the size of the plastic zone with consideration to the elastic-plastic of the rock mass and the condition Coulomb-Mohr strength. On the other hand, Mróz and Kruciński [9] presented a solution showing the impact of the residual strength of rock material with elastic-plastic characteristics on the state of stress and displacement, and the size of disturbed zone around a circular underground excavation. Research on a dry rock mass paved way to a solutions according to the impact of water pressure on the behaviour of the rock material. Shin et al. [15] presented the results of the analysis of the behaviour of the rock mass around the tunnels based on the concept of the response of curve rock mass and taking into account the impact of groundwater percolates.

This paper presents a solution determining the displacement fields in the rock mass around the mine excavations taking into account the presence, in the immediate vicinity of the excavation, zone of reduced capacity (called plastic zone), arising from the impact of stress exceeding the strength criterion of Coulomb-Mohr [5] and the occurrence of elastic area for plastic zone. The solution takes into account a possible increase in volume and a decrease in the strength of the rock material in the plastic zone. Changes in the volume of rock material is controlled by the angle of dilation $\psi$, which in elastic-plastic analysis of the behaviour of the rock mass using failure criterion the Coulomb-Mohr is related to the parameter $\beta$ in the following way [16]:

$$
\beta=\frac{1+\sin \psi}{1-\sin \psi}
$$

The author proved the influence of the parameter $\beta$ and the strength of the rock material after crossing the border state of stress in the field of displacements in the vicinity of the excavation and pressure rock mass on the support of the excavation. The relationships determining the field of displacements in the plastic zone were obtained with consideration to the presence in this zone the elastic and plastic deformation, as well as elastic deformations without.

\section{DESCRIPTION OF THE PROBLEM AND TEST METHOD}

In order to obtain exact solutions describing the behaviour of the rock mass in the vicinity of the excavation mining below listed model simplifications of the considered excavation mining the rock mass were adopted.

Excavation of circular cross-section and a radius (Fig. 1) was made in a homogeneous and isotropic rock mass of elastic-plastic characteristics of the medium. In the rock mass there is a hydrostatic state of primary stress described by component $p$. The inner edge of the excavation is loaded by pressure $p_{a}\left(p_{a} \leq p\right)$. Flat state of strain, independent of the state of stresses along the axis of the pit is assumed. The issue is considered in a polar coordinate system, hence $\sigma_{r}$ is the radial stress and $\sigma_{\theta}$ is the circumferential stress. $\sigma_{1}$ and $\sigma_{3}$ determine the principal stresses, the largest and smallest respectively, acting in the plane of the excavation, and $\sigma_{2}$ means the indirect stress along the main axis of the excavation. Rock mass behaves elastically linearly until the moment when the state of stress does not meet the equation defining the failure criterion. The study adopted Coulomb-Mohr failure criterion, expressed by the principal stresses $\sigma_{1}$ and $\sigma_{3}$ equations [7]:

$$
f_{1}=\sigma_{1}-\sigma_{3}+\left(\sigma_{1}+\sigma_{3}\right) \sin \varphi^{0}-2 c^{0} \cos \varphi^{0}=0 \quad \text { for } \sigma_{1} \geq \sigma_{2} \geq \sigma_{3} ; \sigma_{1} \leq R_{r}^{0}
$$




$$
\begin{gathered}
f_{2}=\sigma_{3}-\sigma_{1}+\left(\sigma_{1}+\sigma_{3}\right) \sin \varphi^{0}-2 c^{0} \cos \varphi^{0}=0 \quad \text { for } \sigma_{3} \geq \sigma_{2} \geq \sigma_{1} ; \sigma_{3} \leq R_{r}^{0} \\
f_{3}=\sigma_{1}-R_{r}^{0}=0 \quad \text { for } \sigma_{1}>R_{r}^{0} \\
f_{4}=\sigma_{3}-R_{r}^{0}=0 \quad \text { for } \sigma_{3}>R_{r}^{0}
\end{gathered}
$$

where $c^{0}, \varphi^{0}$ - consistency and internal friction angle of the rock mass, respectively; $\mathrm{R}_{\mathrm{r}}^{0}$ - the highest tensile stress. form:

Relationship (3) can be converted into a

$$
\sigma_{1}=K^{0} \sigma_{3}-R_{c}^{0}
$$

where $K^{0}=\frac{1+\sin \varphi^{0}}{1-\sin \varphi^{0}} ; \quad \mathrm{R}_{\mathrm{c}}^{0} \quad-\quad$ compressive strength of the rock mass $R_{c}^{0}=\frac{2 c^{0} \cos \varphi^{0}}{1-\sin \varphi^{0}}$

In the rock mass upon reaching the border state of stress (satisfying the Coulomb-Mohr failure criterion (6), equation (6) is applicable for the assumption $\sigma_{1} \geq \sigma_{3}$ ) begins the process of deformation, accompanied by a rapid decrease in the strength of the rock material. Weakened rock material can be further deformed at constant stress. Coulomb-Mohr failure criterion for rock of reduced strength (for the plastic zone or damage (cracked)) is expressed in the equation:

$$
\sigma_{1}=K \sigma_{3}-R_{c}
$$
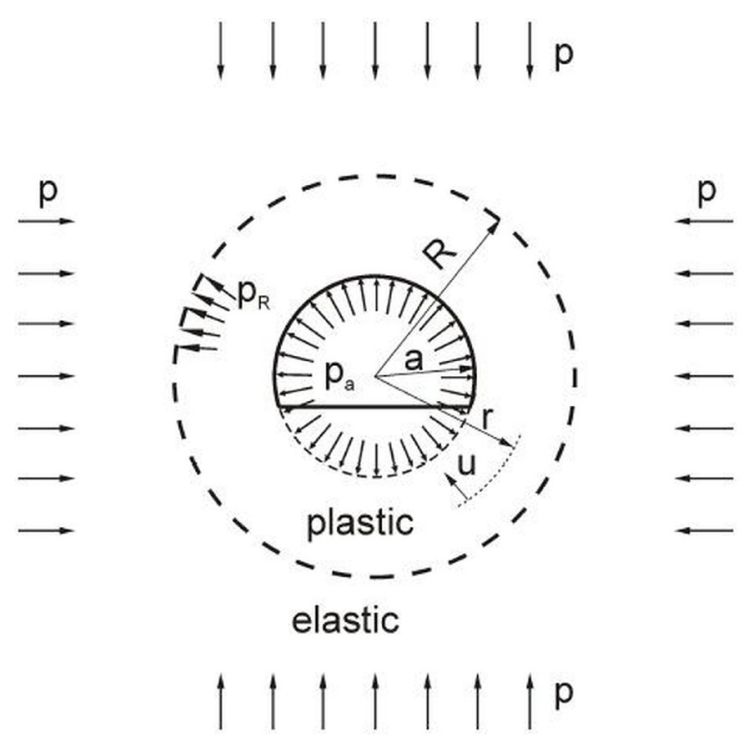

Fig. 1. Geometry and the method of straining the model of the considered rock mass excavation where $K=\frac{1+\sin \varphi}{1-\sin \varphi} ; \mathrm{R}_{\mathrm{c}}$ - compressive strength of the rock mass in the plastic zone; $R_{c}=\frac{2 c \cos \varphi}{1-\sin \varphi} ; \mathrm{c}, \varphi$ - consistency and internal friction angle of the rock mass in the plastic zone, respectively.

It is assumed that the plastic zone is formed in the area adjacent to the edge of the excavation, when the support load-bearing capacity $\mathrm{p}_{\mathrm{a}}$ is lower than the value given by the equation:

$$
p_{a}=\frac{2 p-R_{c}^{0}}{1+K^{0}}
$$

The outside destruction zone of the rock mass behaves elastically.

It is assumed that the equilibrium equation is satisfied in polar coordinates $(\mathrm{r}, \Theta)$ has a form [13]:

$$
\frac{d \sigma_{r}}{d r}+\frac{\sigma_{r}-\sigma_{\theta}}{r}=0
$$

Substituting (7) in the expression (9), taking into account $\sigma_{1}=\sigma_{\mathrm{r}}$ and $\sigma_{3}=\sigma_{\theta}$, and then integrating equation (9) for the boundary condition $\sigma_{r}=-p_{a}$ for $r=a$ we obtain equations describing the state of stress in the plastic zone:

$$
\begin{gathered}
\sigma_{r}=\frac{-R_{c}}{1-K}\left[1-\left(\frac{r}{a}\right)^{K-1}\right]-p_{a}\left(\frac{r}{a}\right)^{K-1} \\
\sigma_{\theta}=\frac{-R_{c} K}{1-K}\left[1-\left(\frac{r}{a}\right)^{K-1}\right]-R_{c}-p_{a} K\left(\frac{r}{a}\right)^{K-1}(11)
\end{gathered}
$$

The state of stress in the elastic zone $(r>R$, Fig. 1) is determined by the equation:

$$
\begin{gathered}
\sigma_{r}=-p\left(1-\frac{R^{2}}{r^{2}}\right)-p_{R} \frac{R^{2}}{r^{2}} \\
\sigma_{\theta}=-p\left(1+\frac{R^{2}}{r^{2}}\right)+p_{R} \frac{R^{2}}{r^{2}}
\end{gathered}
$$


where $\mathrm{p}_{\mathrm{R}}$ - the pressure on the border of the plastic and elastic area; R - radius of the plastic zone.

Pressure $\mathrm{p}_{\mathrm{R}}$ is determined by the equation:

$$
p_{R}=\frac{R_{c}}{1-K}\left[1-\left(\frac{R}{a}\right)^{K-1}\right]+p_{a}\left(\frac{R}{a}\right)^{K-1}
$$

Substituting (12) and (13) at $\mathrm{r}=\mathrm{R}$ in equation (6) is obtained in dependence on the radius of the plastic zone:

$$
\frac{R}{a}=\left\{\frac{(1-K)\left[2 p^{\prime}-1\right]-\frac{R_{c}}{R_{c}^{0}}\left(1+K^{0}\right)}{\left[p_{a}^{\prime}(1-K)-\frac{R_{c}}{R_{c}^{0}}\right]\left(1+K^{0}\right)}\right\}^{\frac{1}{K-1}}
$$

where $p^{\prime}=p / R_{c}^{0}, \quad p_{a}{ }^{\prime}=p_{a} / R_{c}^{0}$.

In the plastic area the total deformation: radial $\varepsilon_{\mathrm{r}}$ and circumferential $\varepsilon_{\theta}$ are the sum of their elastic $\left(\varepsilon_{\mathrm{r}}{ }^{\mathrm{e}}\right.$ and $\varepsilon_{\theta}{ }^{\mathrm{e}}$ respectively) and plastic parts $\left(\varepsilon_{\mathrm{r}}{ }^{\mathrm{p}}\right.$ and $\varepsilon_{\theta}{ }^{\mathrm{p}}$ respectively):

$$
\begin{gathered}
\varepsilon_{r}=\varepsilon_{r}{ }^{e}+\varepsilon_{r}{ }^{p} \\
\varepsilon_{\theta}=\varepsilon_{\theta}{ }^{e}+\varepsilon_{\theta}{ }^{p}
\end{gathered}
$$

Using the law of plastic flow associated with the strength condition (2), expressed by the stress $\sigma_{\mathrm{r}}$ and $\sigma_{\theta}$ and material parameters $(\varphi, c)$ relating to the plastic zone in the form of:

$$
f_{1}=\sigma_{r}-\sigma_{\theta}+\left(\sigma_{r}+\sigma_{\theta}\right) \sin \varphi-2 c \cos \varphi=0
$$

we obtain the following relationships specifying plastic deformations:

$$
\varepsilon_{r}{ }^{p}=\lambda(1+\sin \varphi) \quad \varepsilon_{\theta}{ }^{p}=-\lambda(1-\sin \varphi)
$$

where $\lambda$ - positive parameter of the equation describing the law of plastic flow [9].

On the basis of equations (19) there is ${\varepsilon_{r}}^{p}=-K \varepsilon_{\theta}{ }^{p}$.

Elastic deformations for the plane state of deformation (PSD) are determined by the relationships resulting from Hooke's law [5]:

$$
\begin{gathered}
{\varepsilon_{r}}^{e}=\frac{1+v}{E}\left[\sigma_{r}(1-v)-v \sigma_{\theta}\right] \\
\varepsilon_{\theta}{ }^{e}=\frac{1+v}{E}\left[\sigma_{\theta}(1-v)-v \sigma_{r}\right]
\end{gathered}
$$

where $v$ - Poisson's ratio; E - Young's modulus.

Using relationships (16-17 and 19-21), one can define the total deformations in the plastic area as:

$$
\begin{gathered}
\varepsilon_{r}=\frac{d U}{d r}=\frac{1+v}{E}\left[\sigma_{r}(1-v)-v \sigma_{\theta}\right]+\lambda(1+\sin \varphi) \\
\varepsilon_{\theta}=\frac{U}{r}=\frac{1+v}{E}\left[\sigma_{\theta}(1-v)-v \sigma_{r}\right]-\lambda(1-\sin \varphi)
\end{gathered}
$$

where $\mathrm{U}$ - radial displacement.

Equations (22 and 23) implies the following equation expressing the displacement field in the plastic area:

$$
\frac{d U}{d r}+K \frac{U}{r}=\varepsilon_{r}{ }^{e}+K \varepsilon_{\theta}{ }^{e}
$$


The general form of the equation defining the flat field of displacements in the plastic are including the dilation parameter $\beta$ of rock material are [16]:

$$
\frac{d U}{d r}+\beta \frac{U}{r}=\varepsilon_{r}{ }^{e}+\beta \varepsilon_{\theta}{ }^{e}
$$

Equation (24) is valid when $\beta=\mathrm{K}$, which holds for the associated plasticity and indicates that the dilation angle $\psi$ is equal to the angle of internal friction $\varphi$ of the rock material. Assuming the angle of dilation $\psi>0$ also indicates that the rock material in the zone of destruction increases its volume. If the angle $\psi$ is not known, its maximum value is taken into account in the calculations. When designing and analysing the behaviour of the mining excavations based on Coulomb-Mohr failure criterion, the value $\psi=\varphi$ is taken as the maximum real value of the angle $\psi$.

If $\beta=1(\psi=0)$, then the law of plastic flow is disassociated and there is no change in the volume of rock material.

The solution of equation (25) gives the relationship on the radial displacement in the plastic zone:

$$
U=\frac{1}{r^{\beta}} \int_{R}^{r} r^{\beta}\left({\varepsilon_{r}}^{e}+\beta \varepsilon_{\theta}{ }^{e}\right) d r+C r^{-\beta}
$$

where $\mathrm{C}$ - constant of integration.

Integration constant $\mathrm{C}$ is determined from the condition of continuity of the radial displacement at $r=R$ equals:

$$
C=U_{R}(R)^{\beta}
$$

where $U_{R}$ - radial displacement on the border of the plastic and elastic expressed by the formula [2]:

$$
U_{R}=-\frac{1+v}{E} R\left(p-p_{R}\right)
$$

The exact form of the expression (26) will depend on the method of defining the elastic deformation in the plastic zone.

Method I. It is assumed that in the permanent plastic deformation, elastic deformation is equal to deformations at the border of the plastic and elastic area. Substituting the expression specifying the change in radial $\left(\Delta \sigma_{\mathrm{r}}\right)$ and peripheral $\left(\Delta \sigma_{\theta}\right)$ stress due to performing excavation in elastic medium, in (20) and (21) for $\sigma_{\mathrm{r}}$ and $\sigma_{\theta}$

$$
\begin{gathered}
\Delta \sigma_{r}=\sigma_{r}-p=\left(p-p_{R}\right)\left(\frac{R}{r}\right)^{2} \\
\Delta \sigma_{\theta}=\sigma_{\theta}-p=-\left(p-p_{R}\right)\left(\frac{R}{r}\right)^{2}
\end{gathered}
$$

after assuming $r=R$ we obtain:

$$
\varepsilon_{r}{ }^{e}+\beta \varepsilon_{\theta}{ }^{e}=-\frac{1+v}{E}\left(p-p_{R}\right)(\beta-1)
$$

With the solution (26) taking into account (27), (28) and (31) we obtain the field of elasticplastic displacement:

$$
U=\frac{1+v}{E} \frac{r}{r^{\beta+1}}\left[\left(p-p_{R}\right)(1-\beta)\left(\frac{r^{\beta+1}}{\beta+1}-\frac{R^{\beta+1}}{\beta+1}\right)\right]+U_{R}\left(\frac{R}{r}\right)^{\beta}
$$

Method II. It is assumed that the plastic zone is a thick-walled ring whose edges: $r=R$ outer and inner $\mathrm{r}=\mathrm{a}$ are properly loaded with a uniform pressure $\mathrm{p}_{\mathrm{R}}$ and pressure $\mathrm{p}_{\mathrm{a}}$. For such assumptions elastic deformations define relationships [2]:

$$
\begin{aligned}
& \varepsilon_{r}{ }^{e}=\frac{1+v}{E}\left[(1-2 v) C_{1}+\frac{C_{2}}{r^{2}}\right] \\
& \varepsilon_{\theta}{ }^{e}=\frac{1+v}{E}\left[(1-2 v) C_{1}-\frac{C_{2}}{r^{2}}\right]
\end{aligned}
$$

in which $C_{1}=\frac{\left(p-p_{R}\right) R^{2}-\left(p-p_{a}\right) a^{2}}{R^{2}-a^{2}}, C_{2}=\frac{a^{2} R^{2}\left(p_{R}-p_{a}\right)}{\left(R^{2}-a^{2}\right)}$

Integrating (26) after taking into account (33) and (34), we obtain:

$$
U=\frac{1+v}{E} \frac{r}{r^{\beta+1}}\left\{\left[(1-2 v) C_{1}\right]\left(r^{\beta+1}-R^{\beta+1}\right)-C_{2}\left(r^{\beta-1}-R^{\beta-1}\right)\right\}+U_{R}\left(\frac{R}{r}\right)^{\beta}
$$


Method III. Elastic strain $\varepsilon_{\mathrm{r}}{ }^{\mathrm{e}}$ and $\varepsilon_{\theta}{ }^{\mathrm{e}}$ define the equation:

$$
\begin{gathered}
\varepsilon_{r}{ }^{e}=\frac{1+v}{E}\left\{(1-v)\left[\sigma_{r}-(-p)\right]-v\left[\sigma_{\theta}-(-p)\right]\right\} \\
\varepsilon_{\theta}{ }^{e}=\frac{1+v}{E}\left\{(1-v)\left[\sigma_{\theta}-(-p)\right]-v\left[\sigma_{r}-(-p)\right]\right\}
\end{gathered}
$$

After substituting in (36) and (37) for $\sigma_{\mathrm{r}}$ and $\sigma_{\theta}$, respectively equations (10) and (11) determining stresses in the plastic zone, and then taking into account (36) and (37) in the expression $\left(\varepsilon_{\mathrm{r}}{ }^{\mathrm{e}}+\beta \varepsilon_{\theta}{ }^{\mathrm{e}}\right)$, we obtain:

$$
\varepsilon_{r}^{e}+\beta \varepsilon_{\theta}{ }^{e}=\frac{1+v}{E}\left[D_{1}+D_{2}\left(\frac{R}{a}\right)^{K-1}\right]
$$

wherein

$$
\begin{gathered}
D_{1}=(1-2 v)(1+\beta)\left(p-\frac{R_{c}}{1-K}\right) \\
D_{2}=[(1-v-\beta v)+(\beta-\beta v-v) K]\left(-p_{a}+\frac{R_{c}}{1-K}\right)
\end{gathered}
$$

The field of displacements in the plastic area is obtained from (26) after taking therein into account (38) is defined in the equation:

$$
U=\frac{1+v}{E} \frac{r}{r^{\beta+1}}\left[D_{1} \frac{1}{\beta+1}\left(r^{\beta+1}-R^{\beta+1}\right)+D_{2} \frac{1}{a^{K-1}} \frac{1}{K+\beta}\left(r^{K+\beta}-R^{K+\beta}\right)\right]+U_{R}\left(\frac{R}{r}\right)^{\beta}
$$

If you ignore elastic strain equation defining the field of displacements in the plastic zone, the equation has the following form:

$$
\frac{d U}{d r}+\beta \frac{U}{r}=0
$$

The solution (42) gives the field of plastic displacement in the form of:

$$
U=U_{R}\left(\frac{R}{r}\right)^{\beta}
$$

\section{THE ANALYSIS OF THE IMPACT OF DILATATION AND STRENGTH REDUCTION OF THE ROCK MATERIAL AND THE METHOD OF DESCRIBING DEFORMATIONS IN THE PLASTIC ZONE ON THE BEHAVIOUR OF THE ROCK MASS-EXCAVATION SYSTEM}

Figures 2 and 3 present the curves of radial load of the support that balances radial displacements of the excavation contour obtained from the equation (43), for three values of parameter $\beta=\{1,2,3\}$. Due to the fact that equation (43) was obtained assuming the convention of stress labelling: negative compression, positive tension, the values of displacement radial obtained from the calculations are negative (the direction

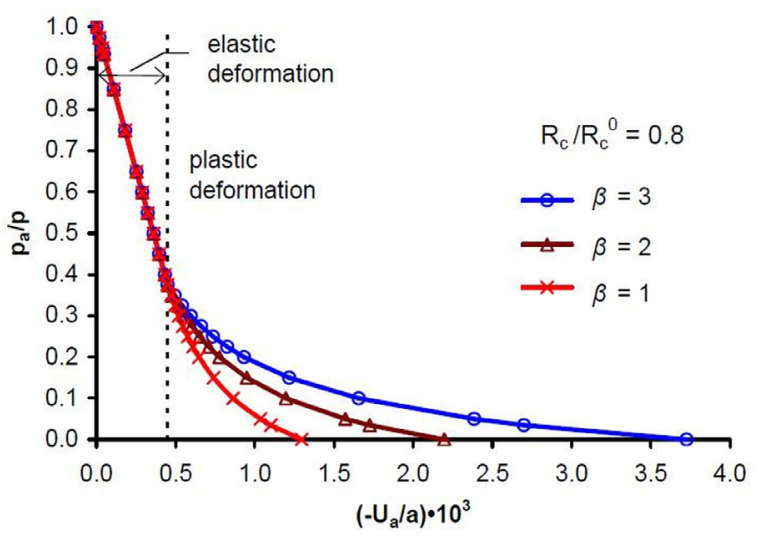

Fig. 2. Curves of rock mass response according to the dilation parameter $\beta$ (field displacement in the plastic area are described in the differential equation (42)) 


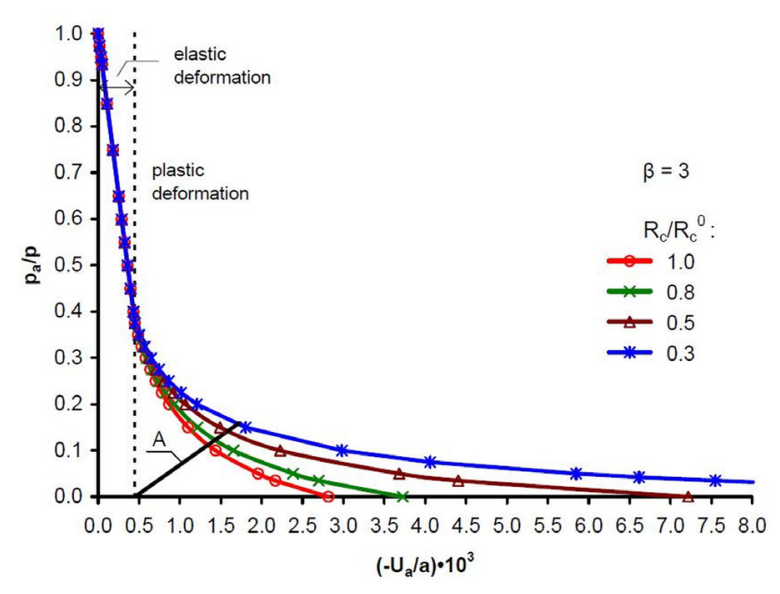

Fig. 3. Impact of $R_{c} / R_{c}{ }^{0}$ on radial displacement contour of the excavation and the value of the pressure exerted on the support (the field of displacements in the plastic area is described by the differential equation (42))

of the movement to the excavation). For the calculations it was assumed that the excavation was made at a depth of $1,000 \mathrm{~m}$ in the rock mass, with an angle of internal friction $\varphi^{0}=\varphi=30^{\circ}$, cohesion $\mathrm{c}^{0}=3.46 \mathrm{MPa}$, compressive strength of the rock mass $\mathrm{R}_{\mathrm{c}}{ }^{0}=12 \mathrm{MPa}$, Young's modulus $\mathrm{E}=50,000 \mathrm{MPa}$, Poisson's ratio $v=0.5$, and a uniform initial pressure $\mathrm{p}=24 \mathrm{MPa}$. The presented results of calculations show that the radial displacement of the excavation contour $\mathrm{U}_{\mathrm{a}}=\mathrm{U}_{\text {for }}$ $=\mathrm{a}$ corresponding to a given support load $\mathrm{p}_{\mathrm{a}}$ obtain the highest value at $\beta=K=3$, in contrast with $\beta=1$ (Fig. 2). For $p_{a} / p=0$ and $R_{c} / R_{c}^{0}=0.8$ the value of the dimensionless measure $\mathrm{U}_{\mathrm{a}} / \mathrm{a}$ for $\beta=$ 3 is about 2.9 times higher than the value of $\mathrm{U}_{\mathrm{a}} / \mathrm{a}$ obtained for $\beta=1$.
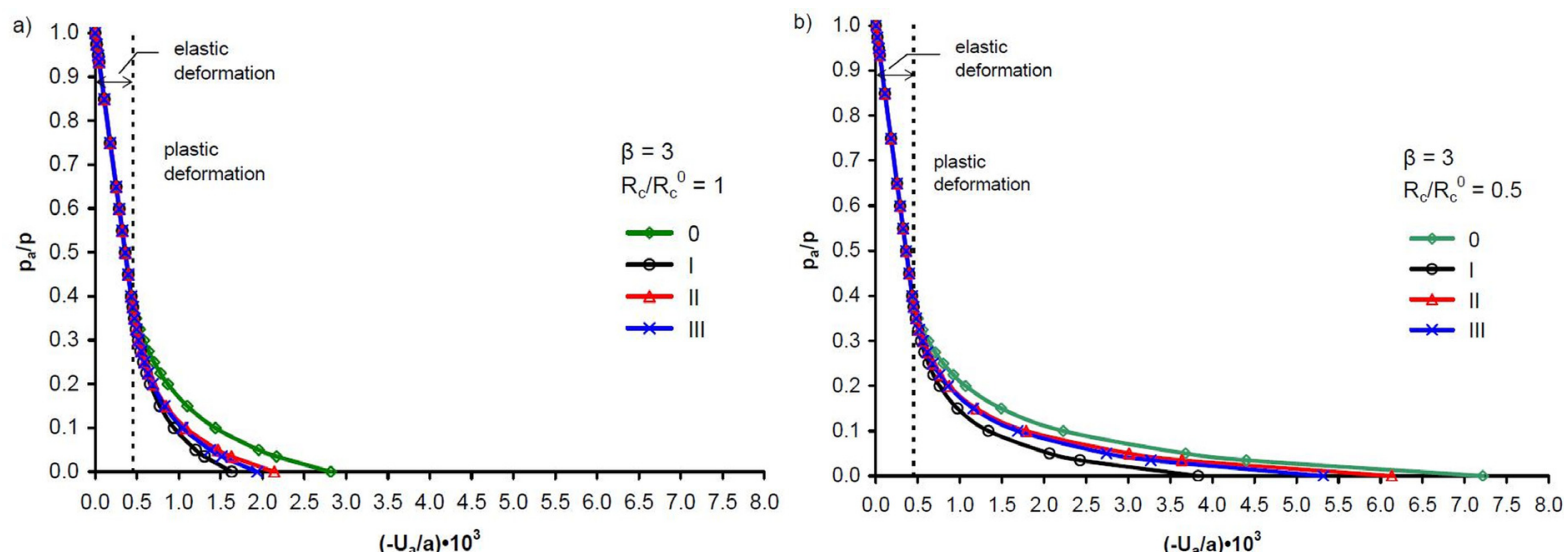

Fig. 4. The course of $U_{a} / a$ changes in the function of $p_{a} / p$ depending on the definition of elastic deformations in
Reducing the strength of the rock material in the plastic are is manifested in the development of cracks in the rock material and the increase in radial displacement towards the excavation (Fig. $3)$. The presented results of calculations for $R_{c} /$ $\mathrm{R}_{\mathrm{c}}{ }^{0}=\{1.0,0.8,0.5,0.3\}$ indicate a significant impact of the decline in the strength of the rock material in the plastic zone in relation to its initial strength at the convergence of the excavation and consequently to increase of the radial load $\mathrm{p}_{\mathrm{a}}$ of the support. The reaction of the casing is illustrated by curve A (Fig. 3).

Flat field of elastic-plastic displacements in plastic area can be described as a (32), (35) or (41). These relationships are the result of the application of I, II or III method of the description of elastic deformations in the plastic area. Figure 4 shows the effect of these three methods for the description of the deformations of the contour of the radial displacement of the excavation, and thus the pressure exerted on the casing. The results of calculations obtained from the dilation parameter $\beta=3$, and for the ratio $\mathrm{R}_{\mathrm{c}} / \mathrm{R}_{\mathrm{c}}{ }^{0}=1.0$ (Fig. $4 \mathrm{a}$ ), and $\mathrm{R}_{\mathrm{c}} / \mathrm{R}_{\mathrm{c}}{ }^{0}=0.5$ (Fig. $4 \mathrm{~b}$ ) are presented. Figure 4 presents the results of further calculations based on equation (43) which determines the visual field of displacements without the elastic deformation in the plastic zone (variant "0"). The presented graphs (Fig. 4) show that the radial displacement of the contour of the excavation reaches the highest values for variant " 0 ". The lowest convergence of the excavation contour occurs for method I of the description of deformations (Eq. (32)), which assumes that in the area of plastic deformation the elastic constants are equal to the deformation at the border of the plastic and elastic zone.

$$
\begin{aligned}
& \text { Fig. 4. The course of } \left.\mathrm{a}_{\mathrm{a}} / \mathrm{a} \text { changes in the function of } \mathrm{p}_{\mathrm{a}} / \mathrm{p} \text { depending on the definiti } \mathrm{R}_{\mathrm{c}} / \mathrm{R}_{\mathrm{c}}^{0}=1.0, \mathrm{~b}\right) \mathrm{R}_{\mathrm{c}} / \mathrm{R}_{\mathrm{c}}^{0}=0.5 \\
& \text { the plastic zone; }
\end{aligned}
$$


The results of the calculations taking into account the ratio $\mathrm{R}_{\mathrm{c}} / \mathrm{R}_{\mathrm{c}}^{0}=0.5$ and $\mathrm{R}_{\mathrm{c}} / \mathrm{R}_{\mathrm{c}}{ }^{0}=1.0$ show that the displacement of rocks in the direction of the excavation for $\mathrm{p}_{\mathrm{a}} / \mathrm{p}$ is greater for $\mathrm{R}_{\mathrm{c}} / \mathrm{R}_{\mathrm{c}}^{0}=0.5$. This applies to each method of describing deformations.

The analysis describing the field of displacements in the plastic zone implies that for dilatation parameter $\beta=1$ and for $v=0.5$ the response curve of the rock mass depicting radial displacement of the excavation contour and radial load balancing thereof $\mathrm{p}_{\mathrm{a}}$ of the support does not depend on the method of defining the elastic deformations in the plastic zone. This means that the changes of the radial displacement of the rock mass with the change of pressure $p_{a}$ is the same for all three methods of describing deformations.

The calculations for $\beta=1$ and for $\nu \neq 0.5$ show the equality of radial displacement values obtained without elastic deformations and determined in accordance with method I of the description of deformations and the equality of displacement contour of the excavation calculated according to methods II and III of deformation description.

The development of plastic zone in the vicinity of the excavation with decreasing pressure $\mathrm{p}_{\mathrm{a}}$ is shown in Figure 5.

The results of calculations presented in Figure 5 show that with the decrease of the strength of the rock material in the plastic zone expressed with parameter $R_{c} / R_{c}^{0}$ range of the plastic zone grows. The increase of pressure $p_{a}$ exerted by the support limits the extent of the plastic zone. Equation (15) shows that in the rock mass with a high angle of internal friction the radius of the plastic zone is smaller. The radius of the plastic zone increases with increasing radius of the excavation and the pressure in the rock mass.

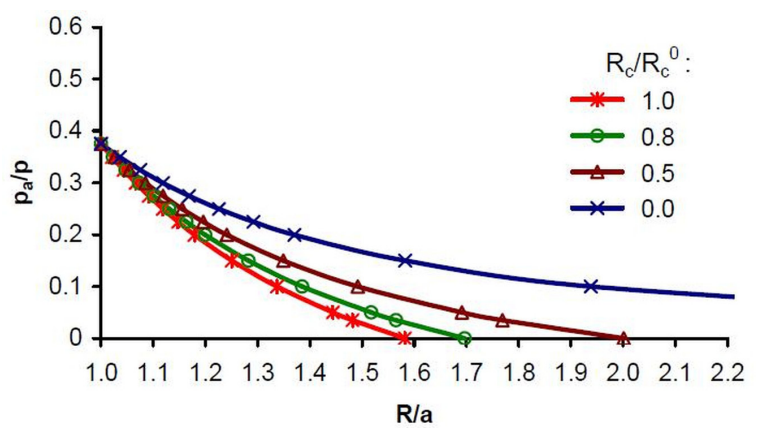

Fig. 5. Development of plastic zone around the mine excavation with decreasing pressure $\mathrm{p}_{\mathrm{a}}$ including the impact of the decrease in the strength of the rock material

\section{CONCLUSIONS}

The analytical solution of determining the state of stress and displacement in the vicinity of mining excavations were obtained assuming the existence of the zone around the excavation with a reduced capacity, which is formed when the rock material reaches extreme tensile strength. The weakening of the rock mass in this area can proceed as a result of the development of cracks. The processes occurring in the plastic zone and its interaction with the resilient region affect the state of stress and strain in the vicinity of the excavation. It can be assumed that the actual state of stress in the vicinity of the excavation will be between the stress state defined on the assumption that the strength of the material in the plastic zone $\mathrm{R}_{\mathrm{c}}=\mathrm{R}_{\mathrm{c}}^{0}$ (elastic-perfectly plastic model of the rock mass) and the state of stress defined under assumption that $\mathrm{R}_{\mathrm{c}}=0$ (elastic-brittle rock mass model). Thus, the elastic-plastic model of the rock taking into account the decrease in the strength of the rock material after reaching the criterion of strength seems to be more appropriate to use in clinical forecasting processes occurring in the vicinity of the excavation compared to the model of elastic-perfectly plastic or elastic-brittle model.

This solution allows the assessment of the impact of decline in the strength of the rock material in the plastic zone on the field radial displacements in the rock mass in the vicinity of the excavation and the radius of the plastic zone. The decrease in the strength of the rock material in the zone of destruction compared to the strength of the initial causes an increase in the excavation convergence with pressure drop $p_{a}$ (Fig. 3). In the depicted in Figure 3, the housing of the response curve (curve A) shows that with the decrease in the strength of the rock material destruction zone increasing pressure on the support of the rock mass.

Clear impact on the course of the response curve of the rock mass has a parameter of dilatation $\beta$. For a given value of the parameter $p_{a}$ higher values of $\beta$ correspond to higher values of radial displacement contour of the excavation.

Field of displacement in the plastic zone depends on whether elastic deformations are ignored or taken into account. On the other hand, if elastic deformations are taken into account, the figure and the numerical value of the expression defining the displacement field in the plastic area depend on the method of forming the definition of the elastic deformation. The calculations carried out 
for the dilatation parameter $\beta=\mathrm{K}=3$ show that the radial displacement of the contour of the excavation reaches the highest values for the variant in which elastic deformations in the plastic zone are ignored. The lowest clamping of excavation contour is obtained for the calculation variant which assumes that in the plastic deformation constants in the plastic zone are equal to the elastic deformation at the border of the plastic and elastic plastic areas. Elastic-plastic displacement in the plastic zone for the case is expressed in the relationship (32). The forms of radial displacement changes of the rock mass as a function of pressure $p_{a}$ for method II and III of defining the elastic deformations are very similar, with slightly higher values of displacements obtained from the calculations based on model II of displacement description.

\section{REFERENCES}

1. Brown E.T., Bray J.W., Ladanyi B. and Hoek E. Ground response curve for rock tunnels. Journal of Geotechnical Engineering, 109(1), 1983, 15-39.

2. Brady B.H.G. and Brown E.T. Rock Mechanics for Underground Mining. Chapman\&Hall, 1993.

3. Carranza-Torres C. Dimensionless graphical representation of the exact elasto-plastic solution of a circular tunnel in a Mohr-Coulomb material subject to uniform far-field stresses. Rock Mechanics and Rock Engineering, 36(3), 2002, 237-253.

4. Carranza-Torres C. Elasto-plastic solution of tunnel problems using the generalized form of the Hoek-Brown failure criterion. International Journal of Rock Mechanics and Mining Sciences, 41(3), 2004, 480-481.

5. Filcek H., Walaszczyk J. and Tajduś A. Metody komputerowe w geomechanice górniczej. Śląskie Wydawnictwo Techniczne, Katowice, 1994.

6. Gschwandtner G.G. and Galler R. Input to the application of the convergence confinement method with time-dependent material behaviour of the support. Tunnelling and Underground Space Technology, 27(1), 2012, 13-22.

7. Izbicki R. and Mróz Z. Metody nośności granicznej w mechanice gruntów i skał. PWN, WarszawaPoznań, 1976.

8. Marczak H. Wpływ spójności górotworu na jego zachowanie się $\mathrm{w}$ otoczeniu wyrobisk korytarzowych. Wiadomości Górnicze, 1, 2013, 15-21.

9. Mróz Z. and Kruciński S. Sprężysto-plastyczna analiza stanu naprężenia i przemieszczenia $\mathrm{w}$ sąsiedztwie wyrobiska kołowego z uwzględnieniem osłabienia materiału skalnego. Archiwum Górnictwa, 29(2), 1984, 205-229.

10. Oreste P. The Convergence-Confinement Method: Roles and Limits in Modern Geomechanical Tunnel Design. American Journal of Applied Sciences, 6(4), 2009, 757-771.

11. Panet M. Le calcul des tunnels par la méthode convergence-confinement. Presses de l'Ecole Nationale des Ponts et Chaussées, 1995.

12. Pilecki Z. Metoda oceny zachowania się masywu skalnego wokół wyrobiska podziemnego. Instytut Gospodarki Surowcami Mineralnymi i Energią PAN, Kraków, 59, 1999.

13. Rułka K. and Stochel D. Obudowy powłokowe dla wyrobisk korytarzowych i komorowych. Zasady projektowania i doboru. Pr. Nauk. GIG, Katowice, 858, 2004.

14. Sharan S.K. Elastic-brittle-plastic analysis of circular openings in Hoek-Brown media. International Journal of Rock Mechanics and Mining Sciences, 40, 2003, 817-824.

15. Shin Y.J., Kim B.M., Shin J.H. and Lee I.M. The ground reaction curve of underwater tunnels considering seepage forces. Tunnelling and Underground Space Technology, 25, 2010, 315-324.

16. Wang Y. Ground response of circular tunnel in poorly consolidated rock. ASCE J. Geotech. Eng., 122, 1996, 703-708. 